\title{
Impacto y memoria de Ortega y Gasset en Ferrater Mora
}

\author{
Impact and Memory of Ortega y Gasset in Ferrater Mora*
}

CARLOS NIETO BLANCO**

\begin{abstract}
Resumen: En esta contribución se expone por vez primera la interpretación que José Ferrater Mora hizo de la obra del filósofo José Ortega y Gasset. Tras ofrecer una breve semblanza intelectual del pensador catalán, se estudia a continuación su correspondencia con Ortega y Gasset, analizando también todos los escritos de Ferrater sobre Ortega, para concluir que, en opinión de Ferrater Mora, Ortega y Gasset es un "pensador vivo", que siempre vuelve.

Palabras clave: exilio, federalismo, futuro, integracionismo, ironía, raciovitalismo, ser, universalidad, vida humana.
\end{abstract}

\begin{abstract}
For the first time, is exposed in this contribution the interpretation that José Ferrater Mora made of the work of the philosopher José Ortega y Gasset. After offering a brief intellectual semblance of the Catalan thinker, his correspondence with Ortega y Gasset is then studied, also analyzing all the writings of Ferrater on Ortega, to conclude that, in the opinion of Ferrater Mora, Ortega y Gasset is a "living thinker", that always comes back.

Keywords: exile, federalism, future, integrationism, irony, rationalism, being, universality, human life.
\end{abstract}

\section{Introducción}

Desde el año 1985 hasta la actualidad he dedicado parte de mi actividad investigadora al estudio de la figura del pensador español José Ferrater Mora (1912-1991), interesándome por todos los campos de su rica y variada actividad intelectual, lo que ha dado lugar a una decena de trabajos académicos publicados, entre los que se encuentra el primer libro sobre el conjunto de su pensamiento filosófico. A lo largo de esta nueva contribución, y dado que en su momento me extendí sobre la presencia del pensamiento orteguiano en la obra de Ferrater Mora (Nieto Blanco, 1985, 211-216-), aspiro a exponer por vez primera la visión que el filósofo catalán mantuvo a lo largo de toda su trayectoria de la obra del filósofo

Recibido: 03/06/2019. Aceptado: 29/08/2019.

* Este trabajo forma parte del Proyecto de Investigación denominado El legado filosófico del exilio español del 39: razón, crítica, identidad y memoria, financiado por el Ministerio de Industria y Competitividad, cuyo número de referencia es FFI2016-70009-R.

** Profesor Titular de Filosofía de la Universidad de Cantabria, carlos.nieto@unican.es LÍNEAS DE INVESTIGACIÓN: a) filosofía moderna y contemporánea: lenguaje, sujeto y acción; b) pensamiento español contemporáneo: ciencia y filosofía. ALGUNAS PUBLICACIONES RECIENTES: La religión contingente, Finalista del XIX Premio Internacional de Ensayo Jovellanos, Oviedo, Nobel, 2013; Memoria e interpretación. Ensayos sobre el pensamiento moderno y contemporánea, Santander, Ediciones Tantín, 2016. 
madrileño José Ortega y Gasset, el cual fue uno de los estímulos que contribuyó a despertar su vocación como escritor y como filósofo. Lo haré dando los siguientes pasos. En primer lugar, acercándome a algunas de las claves de la personalidad de José Ferrater Mora, para pasar a examinar, en segundo lugar, la correspondencia cruzada entre ambos, continuar, en tercer lugar, con los comentarios a su libro sobre Ortega, concluyendo con un análisis interpretativo de los últimos textos que Ferrater Mora nos ha dejado sobre Ortega y Gasset.

\section{Semblanza intelectual de José Ferrater Mora}

José Ferrater Mora nació en Barcelona el 30 de Octubre de 1912, ciudad donde pasó parte de su juventud, trabajando para ganarse la vida en varios oficios de carácter manual y administrativo, al tiempo que realizaba sus estudios de Bachillerato, y cursaba la carrera de Filosofía en la Universidad. El destino quiso que un 31 de Enero de 1991, su ciudad natal fuera también el lugar donde lo sorprendió la muerte, cuando se preparaba para presentar su última novela, La señorita Goldie, cerrando de este modo su círculo vital en el mismo punto geográfico en que se abrió. Los otros puntos sobresalientes de esta circunferencia, a modo de jalones de su existencia, están formados por los países en que le tocó vivir.

Tras la caída del Frente del Este y la derrota del Ejército republicano en el que había combatido, Ferrater Mora cruzó la frontera hispano-francesa camino del exilio en 1939, y lo hizo en compañía de su amigo el pedagogo Herminio Almendros -introductor de la imprenta escolar en España, como método para el aprendizaje de la lectura, siguiendo las orientaciones del pedagogo francés Célestin Freinet-, teniendo París como primera estación provisional de su destierro, según el testimonio de su amigo (Almendros, 2005). En dicha fecha ambos se embarcaron hacia Cuba, donde Ferrater vivió hasta 1941, una estancia que se le hizo insoportable a causa del clima y debido a su mala salud, pero que dejó huella oral y escrita en la cultura de la isla, como se ha puesto de manifiesto en una investigación reciente (Gutierrez Coto, en Ferrater, 2007, 9-24), y cuyo fruto intelectual más importante sería, como luego veremos, la confección y publicación, ese mismo año, de la primera edición de la obra por la que Ferrater Mora sería universalmente conocido, su Diccionario de Filosofía.

Entre 1941 y 1947 -año en que se trasladó a los Estados Unidos de América- se instaló en Chile, una estancia que hemos ido conociendo tanto por el testimonio de personas que compartieron con Ferrater Mora el exilio chileno, así sus amigos Joan Oliver [Pere Quart] (1981; 1988) y el escritor José Ricardo Morales (2000, passim), o su paisano Xavier Benguerel (1982), como por las informaciones de escritores como Josep Pla (1970, 126-176) y las investigaciones de Julio Ortega (1992; 2007, 53-74). Allí entró en contacto con el exilio catalán, participó en la fundación de la Editorial Cruz del Sur, dirigiendo las colecciones “Tierra firme” y Razón y vida" (Morales, 2000, 196-201; Terryn, 2007) y profesó en la Universidad chilena, siendo protagonista de una actividad intelectual desbordante, pues entre 1940 y 1947 , Ferrater Mora dará a la luz nada menos que diez libros y más de cincuenta artículos.

Con la ayuda de una beca de estudios de la Fundación Guggenheim -cuya petición contó con el apoyo de Américo Castro y Pedro Salinas y con la gestión del embajador norteamericano en Chile Claude G. Bowers, que sentía particular simpatía por la España republicana-, se trasladó a Estados Unidos, desempeñando varios puestos docentes en el 
Bryn Mawr College, Pensilvania, desde el año 1949 hasta su jubilación en 1981. Esta era una de tres opciones que según José R. Morales aguardaban a los derrotados en la Guerra Civil, pues si no habían quedado "enterrados", solo les fue dado vivir "aterrados" o "desterrados" (Morales, 2000).

En el año 1943, el filósofo español José Gaos, desde su exilio en México, había propuesto el neologismo transterrados para denominar a aquellos españoles que cambiaron de tierra contra su voluntad, pero no de patria, si por esta se entendía la cultura, siendo la lengua su divisa más importante. Gaos (1949) pensaba no sólo en sí mismo, sino en los que como él encontraron la misma patria, pero en las tierras hispanoamericanas. Durante los años en que Ferrater Mora vivió en Latinoamérica fue un filósofo transterrado, en lo que al castellano se refiere. Pero desde finales de 1947, perdió la condición de tal para adquirir la de simple exiliado. Ahora bien, en la medida en que Ferrater Mora fue una persona bilingüe, siguió siendo un exiliado de su lengua catalana desde que salió de España, pues aunque su obra filosófica se haya fraguado fuera, el pensador catalán mantuvo siempre un contacto permanente con la cultura de su país, primero en el exilio y, a partir de los años cincuenta, con algunas personalidades del interior. Su condición de catalán fue uno más de los rasgos de su identidad personal, como se puso de manifiesto en la correspondencia cruzada con su amigo el poeta Joan Oliver -que firmaba con el seudónimo de Pere Quart-, unidos ambos en torno a su catalanitat (Oliver / Ferrater Mora, 1988), una catalanidad que en el caso de Ferrater la vivió siempre como catalán universal.

De igual modo que sucedió con otros intelectuales que corrieron su misma suerte, para los que el exilio en los Estados Unidos fue una circunstancia que benefició a sus respectivas carreras, salvada la desgracia de la expatriación, Ferrater lo vivió como una oportunidad que la voluble fortuna le había brindado. Por ese motivo no deploró carecer de una lengua "propia", como si no tuviese ninguna, si ello le permitía poder desenvolverse en varias, a tenor de esta lúcida confesión, publicada en catalán, que traducimos:

[...] he considerado que estas páginas podían tener todavía algún interés. En todo caso, constituyen el testimonio de que algunas de mis ideas fueron pensadas en catalán antes de adoptar las formas castellana e inglesa en que han madurado. Supongo que el interés por mi biografía intelectual es escaso, si no es inexistente. Pero estas transformaciones pueden resultar objetivamente curiosas como uno de los "casos", ya no tan excepcionales en nuestra época, de autores que han pasado -que han tenido que pasar- por diversos avatares lingüísticos. Hoy hay un cierto tipo de escritores y de pensadores que pueden ser calificados de esencialmente "desterrados": yo soy un ejemplo. He de decir que no lo deploro. No tener un lengua "propia", no quiere decir necesariamente no tener ninguna lengua: puede querer decir tener varias. En un mundo cada día más universal como el nuestro no es una mala solución (Ferrater Mora: 1961, 8-9).

Y eso fue lo que realmente sucedió, pues sin abandonar nunca su lengua catalana, en la que se expresó sin dificultad hasta el final de sus días, Ferrater Mora fue un políglota, tanto en la expresión oral como escrita. El conocimiento de lenguas extranjeras lo desarrolló siendo muy joven, al tener que hacer de traductor para poder costearse sus estudios, 
y aunque el castellano haya sido la lengua en la que viera la luz la mayoría de sus numerosos escritos, en ocasiones existió una primera versión catalana, inglesa o francesa, que él mismo se encargó de traducir.

Escritor, intelectual, Ferrater Mora es esencialmente un pensador, sin duda el filósofo español más universal de la segunda mitad del siglo XX, y uno de los más destacados de todo el siglo, cuyo nombre habría que añadir a una lista no muy larga formada por Miguel de Unamuno, José Ortega y Gasset, Xavier Zubiri y María Zambrano. Ferrater Mora nos ha legado un estilo de pensar solidario con la riqueza de la realidad, lo que requiere una actitud capaz de comprender y de hacer dialogar a autores y tradiciones diferentes, integrando posiciones y conceptos opuestos para que funcionen de forma complementaria -de manera conjuntiva y no disyuntiva-, una fórmula que hoy sería saludada como tributo a la complejidad de lo real. Y junto a ello, de manera inseparable, nos regala con una escritura diáfana, que fluye con maestría analítica, sutil y transparente.

Las obras de mayor enjundia filosófica son las formadas por la tetralogía $\mathrm{El}$ ser y la muerte, 1962, El ser y el sentido, 1967, De la materia a la razón, 1979, y Fundamentos de Filosofía, 1985, que sustituye parcialmente a la de 1967. Esos libros integran el núcleo filosófico más genuino de nuestro autor, cuya elaboración está presidida por el propósito de edificar una obra original, extendiéndose por todas las disciplinas filosóficas, pero descansando en una filosofía fundamental u ontología. De estas obras, la más atractiva me sigue pareciendo El ser y el sentido, escrita en una prosa filosófica brillante, que Ferrater abandonaría para reemplazarla por otra más austera. Sin embargo, la más completa de las cuatro lo es De la materia a la razón, por cuanto que, sin abandonar el marco teórico de la obra anterior, en esta completa su discurso filosófico con un repertorio formado por nuevas categorías ontológicas. Por otra parte, se trata de una obra más explícita, en cuanto a la autodefinición teórica de su autor, en los términos de un naturalismo de base, desarrollando un materialismo emergentista, al tiempo que nos ofrece también una filosofía moral, o una ética, así como una reflexión metafilosófica (Nieto Blanco, 1985; 1994; 2005).

En Ferrater Mora no hay propiamente una filosofía política, aunque su pensamiento se haya ocupado con frecuencia de la política, con especial referencia en su obra periodística (Ferrater, 1971;1986b; 1994). La manera de adentrarse en esas cuestiones comenzó ya en los primeros años de su estancia Chile, por lo que no es de extrañar que sus escritos más tempranos sobre este asunto arranquen de la doble vivencia que representaba ser exiliado y ser catalán. Y desde esa atalaya, Ferrater Mora, a tono con el proceder ensayístico de los intelectuales españoles de generaciones anteriores, levantará una reflexión de corte históricoculturalista, ideal-típica, que se despliega sobre los Tres mundos: Cataluña, España, Europa, como reza el título de la obra publicada en 1963, y que deja bien a las claras la identidad múltiple de su autor: catalana, española y europea. En éste y en otros escritos de naturaleza similar, el pensador catalán se muestra contrario a cualquier tipo de nacionalismo -fenómeno al que atribuye algunos de los mayores desastres sufridos por Europa a lo largo de su historia-, defiende el bilingüismo para Cataluña, y propone una fórmula federal como organización territorial del Estado español (Nieto Blanco, 2010a).

Semejante propuesta aparece en un ensayo del año 1967 titulado "Unidad y pluralidad" incorporándose a nuevas ediciones del libro anterior y recogido en el volumen primero de sus Obras Selectas (Ferrater, 1967b)-, descrita como la mejor manera de articular la convivencia 
de quienes vivimos en España, un espacio social que la historia nos ha legado como unidad en la diferencia. De acuerdo con el pensador español, el modelo de Estado federal respeta mejor que ningún otro la realidad española, sorteando las dificultades que presentan otras dos fórmulas, a las que también pasa revista. La primera es la secesionista, que conduciría a la independencia de una comunidad territorial, descartada en virtud de la larga historia de convivencia común entre españoles de todas las lenguas y territorios; la segunda es la autonomista, cuya aplicación está amenazada por el límite impreciso que arrastra consigo el propio concepto de autonomía política, fuente de permanente inestabilidad. La propuesta federalista la juzga mucho más consistente teórica y operativamente que el actual Estado de las Autonomías salido de la Constitución de 1978, el cual malamente disimula su naturaleza federal, rasgo que Ferrater Mora caracterizó como "el subyacente federalismo español" (Ferrater, 1983b).

En el libro del año 1944 Les formes de la vida catalana, justamente celebrado y muchas veces reeditado, tanto en catalán como en castellano, Ferrater Mora consideró que la continuidad, el seny, la mesura y la ironía, con todas las cautelas del caso, constituían los cuatro rasgos específicos del modo de ser catalán. Con independencia del valor de esta conjetura, en su momento pensé que tales características bien podrían ser de aplicación a la aportación intelectual del propio Ferrater Mora (Nieto Blanco, 1985, 110-112; 2010a, 149-152), entre la cuales sobresale la ironía, rasgo de su personalidad, a la vez que crisol de los variados, y hasta heterogéneos, materiales de que está formada su obra.

Para concluir esta breve semblanza, podemos señalar que la universalidad es el rasgo que mejor nos puede ayudar a identificar el legado del pensador catalán, la cual puede predicarse de cuatro maneras. En primer lugar, tomando en consideración su condición de exiliado, a la que ya nos hemos referido, que le ofrece la posibilidad de sumergirse en un mundo diverso en formas de vivir, decir y pensar, que Ferrater Mora se apresura a asimilar. En segundo lugar, su universalidad enciclopédica, representada sobremanera por el Diccionario de Filosofía, lo que indujo Juan Marichal a expresar su admiración por este trabajo y sostener que "Ferrater es el español con más lecturas de todo el siglo XX" (Marichal: 1984, 222). Una tercera manifestación del universalismo ferrateriano viene determinada por el propio modo que Ferrater tiene de concebir y de ejercer el pensamiento filosófico, por lo que la denominaré universalidad sistemática, por cuanto que hace referencia a lo que en alguna ocasión el pensador catalán llamó su "sistema", que se va armando en el devenir de la tetralogía formada por sus cuatro grandes obras filosóficas anteriormente citadas. El resultado es una manera de afrontar, exponer y resolver los problemas filosóficos que el propio Ferrater caracterizó desde el principio como “integracionista” (Nieto Blanco, 1985, 87-112). Finalmente, el cuarto y último signo de esa universalidad en la contribución de Ferrater Mora, a la que llamaré universalidad creativa, destaca a nuestro autor como un creador singular, que se desenvolvió, a la vez, en el universo filosófico, literario, y cinematográfico, habiendo cultivado la escritura en géneros tan diversos como la enciclopedia, el tratado, el ensayo, el articulo periodístico, y el relato, tanto en el cuento, como en la novela. En efecto, además de las obras estrictamente filosóficas y de los ensayos de carácter sociopolítico y cultural, junto a su obra periodística (Nieto Blanco, 2016a), en los últimos años de su actividad intelectual Ferrater Mora puso en pie un obra narrativa compuesta por tres libros de relatos (Ferrater, 1979c; 
1985c; 1991c) y cinco novelas (Ferrater, 1982; 1986c; 1988; 1989; 1991b), lo que hado lugar a algunos estudios específicos sobre el tema (Nieto Blanco, 2015; Bardera, 2015). La incursión de Ferrater Mora en el experimento narrativo tiene un precedente dentro de su propia obra, cuando ensaya el género cinematográfico como realizador de una decena de películas de corto o mediometraje entre 1969 y 1973, cuyos guiones dará a la luz en 1974 en un libro titulado Cine sin filosofías (Romaguera Ramió, 1999).

\section{Del joven Ferrater al maestro Ortega: una correspondencia frustrada}

El interés de José Ferrater Mora por el pensamiento de José Ortega y Gasset data de los años 30 del pasado siglo, de sus tiempos de estudiante. Es especialmente significativo que desde esa época, en la que predomina una mezcla de curiosidad y admiración por la figura de Ortega, el pensamiento orteguiano haya acompañado a nuestro autor hasta el final de su vida, adoptando su influencia fórmulas diversas.

Disponemos del testimonio de una persona que lo trató hacia 1932 en una las tertulias que se celebraban en Barcelona, frecuentada por Ferrater Mora. Esta persona fue un maestro segoviano, llamado Norberto Hernanz y Hernanz, que pasó algún tiempo destinado en la Ciudad Condal, fundando posteriormente la revista Escuelas de España, en la que, por cierto, apareció alguna colaboración de Ferrater Mora en el año 1934. En unas memorias todavía inéditas, a las que he podido acceder gracias a la cortesía del Profesor José Luis Mora, el maestro segoviano refiere lo siguiente:

Solía asistir de vez en cuando a una peña que presidía el inspector de Primera Enseñanza Herminio Almendros. Esta era de mayor categoría. Allí se reunían Inspectores, profesores y algún maestro como yo. Almendros era un individuo de acusada personalidad. Serio y concienzudo, certero en sus juicios, sobrio de palabra y cuyas ideas políticas pasaban por muy avanzadas.

A esta peña acostumbraba a asistir un joven, casi imberbe, de unos veinte años, muy fino de modales, pero que a todos nos tenía asombrados por sus conocimientos y erudición. A sus veinte años dominaba el inglés, el francés, el alemán, el latín y el griego. Su memoria era fabulosa. Nos recitaba, cuando venía al caso, párrafos enteros de alguna obra de Ortega y Gasset [la cursiva es mía]. Sus conocimientos de literatura y filosofía sobrepasaban lo corriente. Y lo que era más notable, este chico no tenía otros estudios oficiales que los de la escuela primaria. Yo tuve varias conversaciones con él y creía encontrarme ante una caso como el que había leído de Menéndez Pelayo.

Trabajaba como auxiliar administrativo en una oficina. A todos nos parecía una lástima que se malograra un talento tan extraordinario en tareas burocráticas. Yo tenía alguna amistad con el Sr. Santillana y sabía que desempeñaba algún cargo en la Junta de Ampliación de Estudios, y tuve la pretensión y me atreví a gestionar la concesión de una beca para ayuda de estudios. No conseguí nada, como puede suponerse, dada mi escasa habilidad para estos menesteres. Sin embargo, con el apoyo de Almendros y otros personas generosas, pudo dejar la oficina y cursar los estudios oficiales en la Universidad. 
Hoy aquel joven es el gran filósofo Ferrater y Mora, autor del gran diccionario de filosofía y de buen número de ensayos en los que ha ido exponiendo su teoría del integracionismo (Hernanz, 146-147).

Por aquellos años, el joven Ferrater había recibido el encargo de la Editorial Labor de Barcelona de traducir del alemán al castellano un diccionario de filosofía, que entonces gozaba de cierto renombre, titulado Philosophisches Wörterbuch, cuyo autor era Heinrich Schmidt, publicado en Leipzig (Alfred Kröner Verlag, $1^{\mathrm{a}}$ ed., 1912), cuya octava edición, de 1931, hemos podido consultar, y consta de un volumen en cuarto de $476 \mathrm{pp}$, precedido de un prólogo del autor, así como de un apéndice cronológico, seguido 52 fotografías de filósofos.

A través de las cartas que Ferrater Mora cruzó antes de salir de España con el filósofo argentino de origen español Francisco Romero, recuperadas por una estudiosa también argentina, ahora podemos saber que, además de la traducción propiamente dicha, el pensador catalán se ocupaba de incorporar y actualizar algunas entradas de filósofos latinoamericanos para el Philosophisches Wörterbuch, agradeciendo a su corresponsal, en carta fechada en Barcelona el 2 de Mayo de 1936, la información que recibía de algunos de estos pensadores, según nos comenta la investigadora en cuestión (Jalif de Bertranou, 2013). Todo ello nos traslada hasta los mismos orígenes de lo que sería el propio Diccionario de Filosofía de Ferrater Mora, como nuestro autor ha confesado en más de una ocasión (Maresma, 1990), dando la impresión de que nos encontramos ante una obra que nace al mismo tiempo en que su autor se convierte en escritor. Aquí es donde entra en escena por vez primera el nombre de "Ortega y Gasset, José", así, entrecomillado, pues estaba previsto que fuera una de las nuevas voces que habría de incorporar dicha enciclopedia filosófica, de modo que cuando tiene lista la redacción del artículo decide enviárselo al mismo Ortega para que le transmita su opinión, dando comienzo a una brevísima -y frustrada- correspondencia entre ambos.

El Archivo de Ortega que custodia la Fundación José Ortega y Gasset-Gregorio Marañón contiene las tres cartas que Ferrater Mora dirigió a Ortega y Gasset en el primer Trimestre de 1936, sobre las que se ha llamado la atención en tiempos recientes (Gràcia, 2012, 136-137). En la primera, fechada en Barcelona el 10 de Enero de 1936, le informa de su proyecto de trabajo sobre la novena edición del Diccionario del erudito alemán, y le remite el documento de tres páginas redactado, "con carácter provisional", sobre su pensamiento, rogándole que, "con la mayor celeridad", se lo devuelva con las correcciones o modificaciones que estime oportunas. Dicho texto ha sido recientemente editado -junto con la entrada sobre Ortega Gasset que figura en la primera edición del Diccionario de Filosofía de Ferrater- por la investigadora Esmeralda Balaguer (2017, 199-205), que lo ha acompañado de un interesante estudio introductorio, informando sobre la relación que Ferrtaer Mora mantuvo posteriormente con los hijos de José Ortega y Gasset.

Como el joven Ferrater no encuentra respuesta por parte del filósofo consagrado vuelve a la carga un mes después por medio de una misiva más breve, fechada el 3 de Febrero del mismo año, recordándole la petición anterior, al tiempo que le participa su preocupación por la entrega urgente del original. Ante el reiterado silencio de Ortega, Ferrater, en nueva carta de fecha 5 de Marzo, le agradece que, si sus ocupaciones le impiden satisfacer su petición, "por lo menos, se sirva devolvérmelas [las notas], pues no teniendo copia y haciéndome 
mucha falta me vería precisado a reconstruirlas". En este momento Ortega y Gasset decide responder a su joven corresponsal catalán el 7 de Marzo en una carta de la que, lamentablemente, solo disponemos del comienzo. Pero por la importancia que pueda tener para la relación entre ambos pensadores, poniendo fin a esta malhadada relación epistolar, me permito transcribir la única e incompleta respuesta conservada que Ortega y Gasset traslada a Ferrater Mora. Dice así:

Madrid, 7 de Marzo de 1936

\author{
Sr. D. José Ferrater Mora \\ Pablo Iglesias, 6 \\ Barcelona
}

Muy señor mío: Mi estado de salud me ha impedido contestar a sus cartas y atender a su amable deseo, pero la urgencia que su última carta me manifiesta reclama por mi parte un esfuerzo para de alguna manera corresponderle.

$\mathrm{Su}$ nota me parece en general bien y lo que en ella encuentro de materia a algún ligero reparo no debe ponerse en cuenta ni responsabilidad de usted sino a causas generales sobre las que nunca he querido decir una sola palabra y que por ahora seguiré silenciando.

El espíritu con que está redactada su nota me parece limpio y por eso rompe mi costumbre de no intervenir para nada en lo que los demás digan de mí, sea bueno o sea malo, y me decido a enviarle a usted algunas indicaciones por si cree usted que tuviera algún sentido aprovecharlas. $1^{\circ}$ [y aquí se interrumpe la carta] (Ferrater, 1936).

Es una lástima que nos quedemos sin conocer las observaciones que Ortega había formulado al redactado de Ferrater que, por lo que sabemos, si alguna vez fueron expedidas y este las recibió, no se han encontrado entre su correspondencia. Según propia confesión de Ortega, la "limpieza" con que la nota ferrateriana estaba redactada, debió de actuar de acicate para romper la costumbre de no responder a las críticas, aunque nos quedemos sin saber a qué se refería el filósofo madrileño cuando atribuía a unas misteriosas "causas generales" alguna supuesta incomprensión de su doctrina. Sin duda tales observaciones tenían que expresar algún desacuerdo con la presentación que Ferrater le trasladó de su propio pensamiento.

Hay un ejercicio que roza casi el territorio de la historiografía- ficción con el que calibrar la recepción que habrían podido tener por parte de Ferrater los comentarios de Ortega sobre el trabajo de aquel, que nunca sabremos si logró completarlos. Como también desconocemos, caso de haberlo logrado, si fueron remitidos a su destinatario, de la misma forma que ignoramos si, dados los dos supuestos anteriores, Ferrater Mora los recibió alguna vez.

En lugar de pisar ese terreno pantanoso nos limitaremos a comparar la redacción "provisional" sobre el pensamiento de Ortega y Gasset que Ferrater le envía en 1936, como parte de una de las voces que debería incorporar la versión castellana del Diccionario de Schmidt, con el siguiente texto en orden cronológico que Ferrater Mora escribe 
sobre el filósofo madrileño y que, casualmente, es también una voz -la voz "Ortega y Gasset (José)"-, en esta caso formando parte de la primera edición del Diccionario de Filosofía de José Ferrater Mora, escrito en Cuba, como ya hemos dicho, y publicado en la Editorial Atlante de México en 1941. Fue dicha Editorial una fundación del PSUC en el exilio, dirigida desde sus orígenes por Juan Grijalbo, quien conocía el trabajo de Ferrater en Barcelona, por lo que le encargó la elaboración de la obra con que iba a ser mundialmente conocido. La primera edición del Diccionario de Filosofía consta de 598 páginas a doble columna, y la entada a la que vamos a referirnos sobre Ortega y Gasset (Ferrater, 1941, 404-406) ofrece importantes diferencias con relación al texto "provisional" enviado en 1936.

El texto de este año, comparado con el de 1941, parece un bosquejo, embrión o borrador del que publicará cinco años más tarde. Tiene toda la frescura del descubrimiento, la ilusión o el entusiasmo por el pensamiento del autor estudiado, pero es limitado para hacerse una idea cabal del conjunto del pensamiento de Ortega y Gasset. Hay tres referencias de la redacción "provisional" que han sido descartadas de la entrada en su Diccionario. Una es una remisión interna a la voz "futurición"; otra, una cita de la interpretación del pensamiento de Ortega Gasset debida a Fernando Vela; y, sobre todo, la "prioridad" de Ortega sobre Heidegger en la formulación de algunas conjeturas sobre la vida y la existencia humanas, sobre la que Ferrater insiste en dos momentos.

La entrada sobre Ortega y Gasset que Ferrater Mora incorpora a la primera edición de su Diccionario de Filosofía presenta una gran madurez, demostrando que el intérprete está al cabo de la calle de la totalidad del pensamiento de Ortega hasta esa fecha, cuya doctrina se expone con aplomo y claridad, sin dejarse seducir por la prosa orteguiana, con estilo propio, por tanto. Los tres ejes sobre los que se vertebra el artículo son los siguientes: (i) la superación del idealismo; (ii) las categorías de la vida humana; (iii) el historicismo. Al estar fechada en 1941, Ferrater da como lugar de residencia de Ortega y Gasset la ciudad de Buenos Aires, donde, efectivamente, cumplió una de sus etapas del exilio entre 1936 y 1945. A diferencia del trabajo anterior, no se apoya en ningún intérprete del pensamiento orteguiano, y no insiste en la "prioridad" de Ortega sobre Heidegger, poniendo al mismo nivel las categorías de vida de aquel y el concepto de existencia de este. Al destacar la enorme influencia que ha ejercido el pensamiento de Ortega, Ferrater Mora menciona al final de la entrada los nombres y las obras de los "discípulos" de Ortega, a quienes cita por el siguiente orden: María Zambrano, Xavier Zubiri, José Gaos, Luis Recasens Siches, Manuel García Morente, y Joaquín Xirau, el cual había sido profesor de Ferrater Mora en la Facultad de Filosofía y Letras de Barcelona.

Teniendo en cuanta la fecha en que nos encontrábamos, 1941, el estudio de la figura de Ortega que Ferrater condensa en su entrada de la primera edición del Diccionario es una contribución de primer orden al conocimiento del filósofo español en el mundo hispánico, no solo por su contenido, sino por la oportunidad de darla a la imprenta en fecha tan temprana, lo que marcará la relación constante que Ferrater va a tener con la obra orteguiana. Por ello no es de extrañar que Ferrater Mora otorgase a Ortega y Gasset, junto a Unamuno y D'Ors, el título de "Tres maestros", cuando reunió los estudios a ellos dedicados en sus Obras selectas (Ferrater, 1967b, I, 35-197). 


\section{Los textos publicados por Ferrater sobre Ortega y Gasset hasta la aparición de su libro}

Desde el comienzo de su actividad literaria, Ferrater Mora publicó una serie de ensayos sobre su maestro, que posteriormente incorporó a su libro sobre Ortega y Gasset en sus sucesivas ediciones, razón por cual no he creído oportuno citarlos en la Bibliografía. Son los siguientes: "José Ortega y Gasset", en Cóctel de verdad, Madrid, Literatura, 1935, 69-70; "Ortega y la idea de sociedad", Insula, 119, 1955, 13-20; "De la filosofía a la 'filosofía", Sur, 241, 1956, 21-24; "Una fase del pensamiento de Ortega: El objetivismo", Clavileño, 40, 1956, 11-15, reimpreso en La Torre, 15-16, 1956, 119-126; "Ortega y el concepto de razón vital", Ciclón, 2/1, 1956, 10-16; "Ortega y la idea de la vida humana", Cuadernos del Congreso por la Libertad de la Cultura, 18, 1956, 33-39; "Ortega y Gasset. 1883-1955", International Institute of Philosophy, Philosophy in the mid-century, ed. de R. Klibansky, 4, Firenze: Nuova Italia, 1959, 215-217; "Dos obras maestras españolas", Cuadernos del Congreso por la Libertad de la Cultura, 42, 1960, 47-54; "A Forma radical do saber em Ortega y Gasset", Revista brasileira de filosofía, 11, 1961, 313-321, reimpreso con otro título el mismo año; "On a radical form on thinking", Texas quarterly, 4/1, 1961; "Ensaio introdutório as etapas da filosofía de Ortega y Gasset", in José Ortega y Gasset, Origem e epílogo da filosofía, Rio de Janeiro: Livro Iberoamericano, 1963, 11-145.

Cóctel de verdad fue el primer libro que Ferrater Mora publicó, demostrando con ello una precoz vocación de escritor, y se compone de una serie de ensayos escritos con anterioridad. Uno de sus apartados se titula "Filósofos de hoy, en España", y está integrado por fugaces semblanzas de una galería de pensadores españoles vivos en ese momento. Lo que escribe sobre Ortega y Gasset creo que es significativo porque puede orientar el futuro de su relación con el pensamiento del maestro, como muestra el siguiente párrafo:

De Ortega no puede hablarse ya, si no es en tono de encomio o ditirambo. Lo impediría su monumentalidad filosófica y el cerco de discípulos atentos que constantemente le envuelven. Lo impediría, también, la actitud filial de quien ha bebido en él más que ideas, estilo; más que pensamientos, maneras [la cursiva es mía] (Ferrater, 1935, 69-70).

En 1955 muere José Ortega y Gasset. Justo un año después, en 1956, Ferrater Mora dará a conocer al mundo de habla inglesa el pensamiento del filósofo español, siendo el autor del primer libro de conjunto sobre Ortega, escrito en esa lengua, y uno de los primeros publicados en cualquier otra. Ortega y Gasset: An outline of his philosophy, será su título. Tendrá dos ediciones en inglés, la de 1956 y 1963, y cuatro en castellano: una en Buenos Aires (1958) y tres en España: 1958, 1967 y 1973. Confinaré mi comentario a la última version castellana publicada (Ferrater, 1973).

Quizá una de las novedades más importantes que aporta este libro sea la organización de la hermenéutica ferrateriana sobre la obra de Ortega, subrayando la perspectiva evolutiva de su pensamiento- como así consta en el subtítulo-, para lo cual establece tres etapas; objetivismo, perspectivismo, y raciovitalismo, estadio este último al que otorga la máxima relevancia. 
La obra tiene una clara vocación pedagógica. Ferrater prescinde de la bibliografía secundaria y ofrece una interpretación personal hecha desde la lectura directa de los textos de Ortega, centrada en el legado estrictamente filosófico (ontología, metafísica, epistemología). Para acercar al lector la filosofía de Ortega, Ferrater rechaza situarse dentro de lo que tacha de "pedantería académica", traicionando el espíritu vivo del pensamiento orteguiano. Se propone aplicar a la obra de Ortega el modo narrativo de pensar que el filósofo madrileño propusiera para el tratamiento de la vida humana, con lo cual se convierte en un método biográfico que tiene en cuenta tanto las partes o etapas de su evolución como el todo o el conjunto de su pensamiento desde las cuales estas adquieren sentido. Una fórmula, aunque Ferrater no lo mencione, que nos recuerda lo que hoy conocemos bajo la expresión de "círculo hermenéutico". La aproximación que Ferrater Mora hace del pensamiento de Ortega se basa en una lectura "analítica”, -“limpia”, según sus propias palabras- que permita transitar por la complejidad de una obra como la de Ortega. Está hecha desde una hermenéutica comprensiva, que revela el interés y el aprecio por su filosofía, dialogando con él, tanto en lo que dice como en lo que sugiere. Aunque rehúse el planteamiento expresamente crítico, su análisis es penetrante e incisivo.

Además de destacar la existencia de una etapa "objetivista" en la evolución filosófica de Ortega, llamaría la atención sobre la última parte de su libro, que Ferrater Mora titula "Pensamiento y realidad", con especial referencia al capítulo 2, "La idea del ser" (Ferrater, 1973, 125-140). Este capítulo se adentra en el corazón de la filosofía orteguiana, pues desciende hasta su núcleo ontológico, que es donde se encuentra una de las innovaciones más relevantes de su filosofía, en línea con las revoluciones teóricas que tuvieron lugar a comienzos del siglo XX en el seno del pensamiento europeo continental, pue, si bien, como recuerda Ferrater, la filosofía de Ortega no fue ajena a la de Heidegger, Husserl, Dilthey, Scheler o Bergson, sostiene que se ha desarrollado de un modo independiente (Ferrater, 1973, 128). Tras señalar la deconstrucción orteguiana de la idea de Ser, quizá el legado más antiguo de la tradición filosófica occidental, perdiendo el respeto a tan venerable concepto, Ferrater Mora presenta el giro radical de la ontología orteguiana en los siguientes términos:

Con ello Ortega nos anuncia un "jaque mate" a toda la tradición filosófica. Consiste en negar que el Ser sea tal o cual cosa, o todas las cosas en conjunto: que sea permanente o cambiante, material o espiritual, real o ideal. En rigor, el Ser no "es" nada. No porque sea la Nada, o una nada, sino solo porque no es ninguna entidad, de cualquier especie que sea o pueda concebirse. Lo que llamamos "Ser" no es algo que las cosas tengan de por sí; es más bien algo que "hay que hacer". El Ser es, en suma, quehacer (Ferrater, 1973, 135).

Todo ello remite a un tipo de ontología en la que Ferrater ve la utilización del concepto de ser por parte de Ortega y Gasset como una hipótesis, o como una invención humana, con el fin de dar respuesta a una pregunta que nos hacemos para "salvar las apariencias", con la que capturar la regularidad que ostentan los fenómenos naturales. 


\section{A modo de conclusión: "Ortega y Gasset, el filósofo que siempre vuelve"}

El impacto que el joven Ferrater recibió de la obra de Ortega, a modo de un fuego que puso en combustión su personalidad intelectual, nunca logró apagarse a lo largo de su trayectoria vital, razón por cual, una vez desaparecido el maestro, y cesada la influencia personal más cercana, Ferrater Mora cultivó la memoria de su obra, como un ejercicio de fidelidad a la realidad, entre la que siempre se encuentra el valor y el cuidado, si no de las ideas, sí del "estilo" y las "maneras" orteguianas, como nos recordaba en su evocación del año 1935. A la hora de concluir, pues, me importa hacer con nuestro autor un ejercicio de memoria sobre Ortega y Gasset, a quien Ferrater Mora siempre otorgó el mérito de haber elevado el castellano a la altura de lengua filosófica.

En el Prefacio a la obra sobre Ortega y Gasset que acabamos de comentar Ferrater viene decirnos algo así como que donde menos te lo esperas salta la libre orteguiana, subrayando que su pensamiento se halla más próximo al actual de lo que muchas veces se cree, por muy diferentes que sean sus presupuestos, y como muestra de ello nos recuerda su propia experiencia. Cuando se hallaba preparando un libro, que finalmente aparecería 1974 -una obra que se reveló como una suerte de ajuste de cuentas con la filosofía analítica titulada Cambio de marcha en filosofía-, sin buscarlo, Ferreter Mora volvió a encontrase con el pensamiento orteguiano. En efecto, en su discusión de la filosofía de Feyerabend introduce una larguísima nota, la nota 37 (Ferrater, 1974, 41-45), en la que de pronto aparece Ortega para aprovechar su distinción entre ideas y creencias a propósito de la presencia de marcos conceptuales y/o culturales que se alejan del empirismo estricto. Por supuesto que Ortega y Gasset sigue presente en las sucesivas ediciones de su Diccionario de Filosofía, hasta ocupar una dilatada extensión en la sexta y última edición que publicó (Ferrater, 1979b, III, 2661-2665).

Veamos ya los últimos escritos sobre Ortega.

"Ortega, el filósofo que siempre vuelve", título con el que hemos encabezado esta sección de nuestra investigación, es un artículo periodístico. Se publica con motivo del veinticinco aniversario de la muerte de Ortega. Su argumento viene a justificar la tesis de que la obra de Ortega, como obra abierta que es, está viva y se mueve con el tiempo, por lo cual aparece y reaparece desafiando al pensamiento actual. De pronto nos sorprende en un recodo del camino con una intuición o una idea que sale a nuestro encuentro, iluminando el presente. Y concluía de este modo, confesando que la obra de Ortega:

[...] una compleja masa de pensamientos que nos orienta sin que necesitamos por ello seguirla. Es ella la que viva, alerta y latiente, nos sigue (Ferrater, 1980).

"Tres actitudes ante Ortega", es también otro artículo de periódico, una de las muchas facetas en que se prodigó la escritura de Ferrater Mora, y que en este caso conmemora el centenario del nacimiento de Ortega. Confiesa que fue un mentor espiritual para la gente de su generación, o un guía indispensable para orientarse en el pensamiento contemporáneo. Las tres actitudes son la reverente, la hostil y la crítica, que es la defendida por Ferrater. Dice de ella: 
En rigor, se sitúa ante el filósofo críticamente sólo porque estima que las ideas y los argumentos son de suficiente valor como para que sean sometidos a escrutinio (Ferrater, 1983c).

“Ortega, filósofo del futuro", es un artículo de Revista que reproduce el texto leído en la Biblioteca del Congreso de Washington (EE.UU.) en un acto dedicado a honrar su memoria, durante los días 29 de septiembre a 1 de Octubre de 1984.

Ferrater Mora plantea una hipótesis contrafáctica sobre lo que hubieran respondido Ortega y Unamuno caso de ser interrogados sobre su inmortalidad. Sugiere que el primero hubiera guardado silencio, mientras que el segundo se hubiese prodigado en la respuesta. Centrándose en Ortega, Ferrater repasa su concepción de la vida humana -especialmente "las categorías de la vida" que se encuentran en la obra ¿Qué es filosofía?-, destacando la presencia del tiempo futuro como condición de posibilidad de la necesidad decidir, lo Ortega y Gasset categorizó con el neologismo futurición. Haciendo en este caso que prime una ontología del futuro frente a la del pasado, Ferrater sugiere que Ortega se sirve de una lógica modal tomada en sentido informal, lo que explica del siguiente modo:

Hay muchas cosas entre las que Ortega declaró que son todavía harto interesantes [...] En rigor, Ortega dijo una serie de cosas muy iluminadoras sobre asuntos no estrictamente filosóficos [...] Pero como no pocas de las cosas, filosóficas o no filosóficas que dijo en cualquier momento, pueden ser distintas de las que dijo, o hubiera podido decir, luego, es más razonable y, de hecho, más “orteguiano" no preocuparse por la letra y empezar a interesarse por el espíritu de la letra. [...] Puesto que Ortega recomendaba constantemente estar a la altura de los tiempos, sería poco fiel a su espíritu permanecer atado a un tiempo que ya pasó (Ferrater, 1984, 131).

Es a este espíritu al que, con independencia de las tesis filosóficas que cada uno defendió, Ferrater Mora permaneció siempre fiel, cuidando o "salvando" -como hubiera dicho Ortegala realidad, comprometido con la tarea de insertar la racionalidad en la vida humana, del mismo modo que su maestro llevó la vida a la razón, lo que produjo el temprano impacto que Ferrater Mora fue transformando en memoria a lo largo de su vida.

\section{Bibliografía}

Almendros, H. (2005), Diario de un maestro exiliado (Barcelona, 1939 - La Habana, 1940), ed. de A. Blat y C. Doménech, Valencia: Pre-Textos.

Balaguer, E. (2017), "La circunstancia indecible. El Diccionario de Filosofía: vínculo entre dos filósofos", Revista de Estudios Orteguianos, 35, pp. 191-205.

Bardera Poch, D. (2015), Anàlisi del l'obra narrativa de Ferrater Mora des de la seva filosofía, Tesis Doctoral dirigida por Josep-Maria Terribacras, Girona: Universitat de Girona.

Benguerel, X. (1982), Memòria d'un exili: Xile 1940-1952, Barcelona: Edicions 62.

Ferrater Mora, J. (1935), Cóctel de verdad, Madrid: Ediciones Literatura.

Ferrater Mora, J. (1936), "Correspondencia Ferrater Mora / Ortega y Gasset", Archivo de José Ortega y Gasset, Madrid: Fundación José Ortega y Gasset y Gregorio Marañón. 
Ferrater Mora, J. (1941), Diccionario de Filosofía, México, Atlante.

Ferrater Mora, J. (1956), Ortega y Gasset: An outline of his philosophy, London: Bowes \& Bowes, y New Haven, Conneticut: Yale University.

Ferrater Mora, J. (1961), Una mica de tot, Palma de Mallorca: Moll.

Ferrater Mora, J. (1962), El ser y la muerte. Bosquejo de una filosofía integracionista, Madrid: Aguilar.

Ferrater Mora, J. (1967a), El ser y el sentido, Madrid: Revista de Occidente.

Ferrater Mora, J. (1967b), Obras selectas, 2 vols., Madrid: Revista de Occidente.

Ferrater Mora, J. (1971), El hombre y su medio y otros ensayos, Madrid: Siglo Veintiuno.

Ferrater Mora, J. (1973), Ortega y Gasset: etapas de una filosofía, Barcelona: Seix Barral.

Ferrater Mora, J. (1974a), Cambio de marcha en filosofía, Madrid: Alianza.

Ferrater Mora, J. (1974b), Cine sin filosofías, Madrid: Esti-Arte, introducción de A. Sánchez-

Harguindey.

Ferrater Mora, J. (1979a), De la materia a la razón, Madrid: Alianza.

Ferrater Mora, J. (1979b), Diccionario de Filosofía, 4 vols., 6 a ed., Madrid: Alianza,

Ferrater Mora, J. (1979c), Siete relatos capitales, Barcelona: Planeta.

Ferrater Mora, J. (1980), "Ortega, el filósofo que siempre vuelve”, El País, 8 de Octubre de 1980.

Ferrater Mora, J. (1981), Ética aplicada, Madrid: Alianza, 2a ed., 1988.

Ferrater Mora, J. (1982), Claudia mi Claudia, Madrid: Alianza.

Ferrater Mora, J. (1983a), El mundo del escritor, Barcelona: Crítica.

Ferrater Mora, J. (1983b), "El subyacente federalismo español”, Anuario El País, 93.

Ferrater Mora, J. (1983c), "Tres actitudes ante Ortega”, El País, 7 de Mayo de 1983.

Ferrater Mora, J. (1984), “Ortega, filósofo del futuro”, Cuadernos hispanoamericanos, 403405, pp. 121-131.

Ferrater Mora, J. (1985a), Fundamentos de filosofía, Madrid: Alianza.

Ferrater Mora, J. (1985b), Modos de hacer filosofía, Barcelona: Crítica.

Ferrater Mora, J. (1985c), Voltaire en Nueva York, Madrid: Alianza.

Ferrater Mora, J. (1986a), Hecho en Corona, Madrid: Alianza.

Ferrater Mora, J. (1986b), Ventana al mundo, Barcelona: Anthropos.

Ferrater Mora, J. (1988), El juego de la verdad, Barcelona: Destino.

Ferrater Mora, J. (1989), Regreso del infierno, Barcelona: Destino.

Ferrater Mora, J. (1991b), La señorita Goldie, Barcelona: Seix-Barral.

Ferrater Mora, J. (1991c), Mujeres al borde de la leyenda. Con un prólogo del autor y un epílogo de Priscilla Cohn que incluye el relato póstumo de José Ferrater Mora "Reivindicación de Babel", Barcelona: Círculo de Lectores.

Ferrater Mora, J. (1994), Mariposas y supercuerdas. Diccionario sobre nuestro tiempo, presentación de P. Cohn, Barcelona: Península.

Ferrater Mora, J. (2005), Variaciones de un filósofo. Antología, selección, estudio introductorio y edición de J. Gracia, A Coruña: Edicios do Castro.

Ferrater Mora, J. (2007), Razón y verdad y otros ensayos, ed. y prólogo de A. F. Gutiérrez Coto, Sevilla: Espuela de Plata.

Ferrater Mora, J., Epistolario, Girona, Universitat de Girona. Disponible en: http://dugifonsespecials.udg.edu/handle/10256.2/2 
Gaos, J. (1949), "Los transterrados españoles de la filosofía en México", Filosofía y Letras, 36 , pp. 207-231.

Gràcia, J. (2012), Burguesos Imperfectes. L'ètica de l'heterodòxia a les lletres catalanes del segle XX, Barcelona: La Magrana, pp. 127-160.

Hernanz y Hernanz, N., Memorias [inéditas], Segovia.

Jalif de Bertranou, C. A. (2013), "Francisco Romero y sus cartas con intelectuales españoles exiliados", Revista de Hispanismo Filosófico, 18, pp. 89-114.

Maresma, A. ( 1990), “Josep Ferrater Mora” [Entrevista], Catalònia, 17, pp. 32-36.

Marichal, J. (1984), Teoría e historia del ensayismo hispánico, Madrid: Alianza.

Morales, J. R. (2000), "El arte de enterarse (El destierro en el pensamiento de José Ferrater Mora)", en Ensayos en suma. Del escritor, el intelectual y sus mundos, Madrid: Biblioteca Nueva, pp. 195-218.

Nieto Blanco, C. (1985), La filosofía en la encrucijada. Perfiles del pensamiento de José Ferrater Mora, prólogo de J. Muguerza, Barcelona: Servicio de Publicaciones de la Universidad Autónoma.

Nieto Blanco, C. (1994), "Naturalismo filosófico y dialéctica en el pensamiento de José Ferrater Mora", en Giner, S. y Guisán, E. (eds.), José Ferrater Mora: el hombre y su obra, Santiago de Compostela: Universidade de Santiago de Compostela, pp. 15-36.

Nieto Blanco, C. (2005), "El mundo desde dentro. Una aproximación al discurso ontológico de Ferrater Mora", Revista de Hispanismo Filosófico, 10, pp. 59-72.

Nieto Blanco, C. (2010a), "Cultura y política en el pensamiento de José Ferrater Mora", en Sánchez Cuervo, A. y Hermida de Blas, F (coords.), Pensamiento exiliado español. El legado filosófico del 39 y su dimensión iberoamericana, Madrid: Biblioteca Nueva/ CSIC, pp. 126-163.

Nieto Blanco, C. (2010b), "Idioma y filosofía en el pensamiento de José Ferrater Mora", en Mora García, J.L., Mandado Gutiérrez, R.E., Gordo Pieñar, G., Nogueroles Jové, M. y Fundación I. Larramendi (eds.), La filosofía y las lenguas de la península Ibérica, Madrid: Fundación Ignacio Larramendi / Asociación de Hispanismo Filosófico / Real Sociedad Menéndez Pelayo / Societat Catalana de Filosofia, pp. 295-322.

Nieto Blanco, C. (2012), "José Ferrater Mora: actualidad de un centenario", Asociación de Hispanismo Filosófico, www.ahf-filosofia.es.

Nieto Blanco, C. (2015), "El escritor y su mundo: narratividad y filosofía en la obra de Ferrater Mora”, en ACTAS - www.redfilosofia.Vol. XIV, pp. 13 - 28.

Nieto Blanco, C. (2016a), "El escritor y su mundo: narratividad y periodismo en la obra de José Ferrater Mora", en Macciuci, R. (ed.), http: //congresoespanyola.fahce.unilp.edu. ar, pp. $1-23$.

Nieto Blanco, C. (2016b), "Ferrater Mora: un liberalismo de raíz ética", en Sánchez Cuervo, A. (ed.), Liberalismo y socialismo. Cultura y pensamiento político del exilio español de 1939, Madrid: Consejo Superior de Investigaciones Científicas, pp. 35-75.

Oliver, J. [Pere Quart] (1981), "Notes on a Friendship”, en Cohn, P. (ed.), Transparencies. Philosophical Essays in Honor of J. Ferrater Mora, Atlantic Highlands, N.J.: Humanities Press, pp. 1-4.

Oliver, J. i Ferrater Mora, J. (1988), a cura d'Antoni Turull, Joc de cartes 1948-1984, Barcelona: Edicions 62. 
Ortega Villalobos, J. (1992), "Entrevista con Ferrater Mora sobre su estancia en Chile", Boletín de la Institución Libre de Enseñanza, 15, pp. 87-89.

Ortega Villalobos, J. (2007), "L'estada de Ferrater Mora a Xile: Filosofia i exil”, en Terricabras, J. Ma . (ed.), La filosofía de Ferrater Mora, Girona: Documenta Universitaria, pp. 53-74.

Pla, J. (1970), Homenots. Segona Sèrie, en Obra completa, XVI, Barcelona: Destino, 1970, pp. 127-176.

Romaguera Ramió, J. (1999), “Josep Ferrater i Mora: escriptor cinematográfic: cineasta”, Revista de Catalunya, 145, pp. 53-73.

Terryn, N. (2007), "Josep Ferrater Mora, José Ricardo Morales i l'Editorial Cruz del Sur a Xile", en Terricabras, J. $\mathrm{M}^{\mathrm{a}}$. (ed.), La filosofía de Ferrater Mora, Girona: Documenta Universitaria, pp. 75-92. 